\title{
Structural bases of GM1 gangliosidosis and Morquio B disease
}

\author{
Mizuki Morita $^{1,6}$, Seiji Saito ${ }^{2,6}$, Kazuyoshi Ikeda ${ }^{3,7}$, Kazuki Ohno ${ }^{3,8}$, Kanako Sugawara ${ }^{4}$, Toshihiro Suzuki ${ }^{5}$, \\ Tadayasu Togawa ${ }^{5}$ and Hitoshi Sakuraba ${ }^{4,5}$
}

Allelic mutations of the lysosomal $\beta$-galactosidase gene cause heterogeneous clinical phenotypes, such as GM1 gangliosidosis and Morquio B disease, the former being further classified into three variants, namely infantile, juvenile and adult forms; and heterogeneous biochemical phenotypes were shown in these forms. We tried to elucidate the bases of these diseases from a structural viewpoint. We first constructed a three-dimensional structural model of human $\beta$-galactosidase by means of homology modeling. The human $\beta$-galactosidase consists of three domains, such as, a TIM barrel fold domain, which functions as a catalytic domain, and two galactose-binding domain-like fold domains. We then constructed structural models of representative mutant $\beta$-galactosidase proteins (G123R, R201C, I51T and $\mathrm{Y} 83 \mathrm{H}$ ) and predicted the structural change associated with each phenotype by calculating the number of affected atoms, determining the root-mean-square deviation and the solvent-accessible surface area, and by color imaging. The results show that there is a good correlation between the structural changes caused by amino-acid substitutions in the $\beta$-galactosidase molecule, as well as biochemical and clinical phenotypes in these representative cases. Protein structural study is useful for elucidating the bases of these diseases.

Journal Human Genetics (2009) 54, 510-515; doi:10.1038/jhg.2009.70; published online 31 July 2009

Keywords: $\beta$-galactosidase; GM1 gangliosidosis; Morquio $\mathrm{B}$ disease; protein structure

\section{INTRODUCTION}

Lysosomal $\beta$-galactosidase (EC 3.2.1.23; $\beta$-Gal) hydrolyzes the terminal $\beta$-galactosyl residues of glycoconjugates, including GM1 ganglioside, glycoproteins and glycosaminoglycans. Deficiencies of $\beta$-Gal cause human metabolic disorders with heterogeneous clinical phenotypes, such as GM1 gangliosidosis (MIM no. 230500) and Morquio B disease (MIM no. 253010). ${ }^{1}$

GM1 gangliosidosis is a neurosomatic disease involving progressive neurological deterioration characterized by the accumulation of GM1 ganglioside in neural cells. The prevalence of GM1 gangliosidosis has been estimated to be 1 in 100000-200000 live births, ${ }^{2}$ and it can be categorized into three phenotypic variants, namely the infantile, juvenile and adult forms. Morquio B disease is a very rare genetic disease defined as generalized skeletal dysplasia associated with keratan sulfaturia. As mentioned above, a deficiency of $\beta$-Gal activity causes several phenotypes, but the details have not yet been determined.

So far, more than 100 gene mutations causing GM1 gangliosidosis and Morquio B disease have been reported. ${ }^{3}$ Among them, gross alterations of the $\beta$-Gal gene have been generally found in patients with the infantile form of GM1 gangliosidosis, but missense mutations comprising the majority of gene mutations have been identified in various phenotypes.

As a chemical chaperone for mutant $\beta$-Gals resulting from some missense mutations has been developed for enzyme enhancement therapy for GM1 gangliosidosis and Morquio B disease, ${ }^{4}$ prediction of the clinical outcomes of the diseases is becoming more and more important for determining the appropriate therapeutic methods. To elucidate the bases of GM1 gangliosidosis and Morquio B disease, structural information on defective $\beta$-Gals is very important. However, only few reports on this issue have been published.

In this study, we constructed structural models of representative mutant $\beta$-Gal proteins resulting from amino-acid substitutions associated with various phenotypes of GM1 gangliosidosis and Morquio B disease. We then examined the structural changes involved by calculating the numbers of atoms influenced by amino-acid substitutions, and by determining the root-mean-square deviation (RMSD) and the solvent-accessible surface area (ASA). Furthermore, we examined the distributions and degrees of three-dimensional structural changes caused by these mutations through color imaging.

\footnotetext{
${ }^{1}$ Agricultural Bioinformatics Research Unit, Graduate School of Agricultural and Life Sciences, The University of Tokyo, Tokyo, Japan; ${ }^{2}$ Department of Biotechnology, Graduate School of Agricultural and Life Sciences, The University of Tokyo, Tokyo, Japan; ${ }^{3}$ NPO for the Promotion of Research on Intellectual Property Tokyo, Tokyo, Japan; ${ }^{4}$ Department of Clinical Genetics, Meiji Pharmaceutical University, Tokyo, Japan and 5Department of Analytical Biochemistry, Meiji Pharmaceutical University, Tokyo, Japan 6These authors contributed equally to this work.

${ }^{7}$ Current address: Pharma Design, 2-19-8, Hatchobori, Chuo-ku, Tokyo 104-0032, Japan.

${ }^{8}$ Current address: Astellas Pharma, 21 Miyukigaoka, Tsukuba, Ibaraki 305-8585, Japan.

Correspondence: Professor H Sakuraba, Department of Analytical Biochemistry, Meiji Pharmaceutical University, 2-522-1 Noshio, Kiyose, Tokyo 204-8588, Japan.

E-mail: sakuraba@my-pharm.ac.jp

Received 17 April 2009; revised 3 June 2009; accepted 22 June 2009; published online 31 July 2009
} 


\section{MATERIALS AND METHODS}

\section{Structural modeling of the human $\beta$-Gal protein}

A structural model of human $\beta$-Gal was constructed using molecular modeling software, MODELLER (http://www.salilab.org/modeller/), developed by Sali and Blundell. ${ }^{5,6}$ As a template, the crystallographic structure of $\beta$-Gal from Bacteroides thetaiotaomicron (PDB ID: 3D3A) was used, and the pairwise sequence alignment between the target and the template was obtained from HHpred (http://toolkit.tuebingen.mpg.de/hhpred). ${ }^{7}$ The overall and local qualities of the model were assessed using Verify3D (http://nihserver.mbi.ucla. edu/Verify_3D/), ${ }^{8,9}$ ProSA (http://www.came.sbg.ac.at/typo3/index.php?id= prosa), ${ }^{10,11}$ ProQ (http://www.sbc.su.se/ bjornw/ProQ/), ${ }^{12}$ ProQres (http:// www.sbc.su.se/ bjornw/ProQ//) ${ }^{13}$ and DFIRE (http://sparks.informatics.iupui. edu/hzhou/dfire.html), ${ }^{14}$ and by comparing the conformation of the active site residues with that of the crystallographic structure of Penicillium sp. $\beta$-Gal. ${ }^{15}$ The disordered regions were predicted using DISOPRED2 (http://bioinf.cs. ucl.ac.uk/disopred/), ${ }^{16}$ POODLE (http://mbs.cbrc.jp/poodle/) ${ }^{17,18}$ and PrDOS (http://prdos.hgc.jp/). ${ }^{19}$

\section{Representative amino-acid substitutions causing GM1 gangliosidosis and Morquio $\mathrm{B}$ disease}

In this study, we analyzed four representative amino-acid substitutions for which the clinical and biochemical phenotypes have been clearly described, that is, G123R (the infantile form of GM1 gangliosidosis), R201C (the juvenile form of GM1 gangliosidosis), I51T (the adult form of GM1 gangliosidosis) and Y83H (Morquio B disease). ${ }^{20-24}$

\section{Determination of ASA of amino-acid residues}

The ASA of each amino-acid residue in human $\beta$-Gal was calculated using ACCESS. ${ }^{25}$

Structural modeling of mutant $\beta$-Gal proteins and calculation of the numbers of atoms influenced by the amino-acid substitutions Structural models of mutant $\beta$-Gals were constructed using the molecular modeling software, TINKER (http://dasher.wustl.edu/tinker/), developed by
Ponder and colleagues (Department of Biochemistry and Molecular Biophysics, Washington University). ${ }^{26-30}$ As a template, a homology model of the human $\beta$-Gal protein was used, and energy minimization was performed. The rootmean-square gradient value was set at $0.05 \mathrm{kcal} \mathrm{mol}^{-1} \AA$. Each mutant model was then superimposed on the wild-type structure based on the $C \alpha$ atoms using the least-square-mean fitting method. ${ }^{31,32}$ We reported that the structure was influenced by an amino-acid substitution when the position of an atom in a mutant differed from that in the wild type by more than the cutoff distance $(0.15 \AA)$ on the basis of the total RMSD, as described previously. ${ }^{32}$ We calculated the numbers of influenced atoms in both the main chain and the side chain.

\section{Determination of RMSD values for all atoms in the mutant $\beta$-Gal proteins}

To determine the influence of the amino-acid substitutions on conformational changes in $\beta$-Gal, the RMSD values for all atoms in the mutant $\beta$-Gals were calculated according to the standard method. ${ }^{33}$

Color imaging of the atoms influenced by the amino-acid substitutions

Color imaging of the influenced atoms in the three-dimensional structures of the mutant $\beta$-Gals was performed for the amino-acid substitutions. The analysis was based on the differences between the wild types and mutants to determine the influence of the amino-acid substitutions geographically and semi-quantitatively according to the method described previously. ${ }^{32}$

\section{RESULTS}

Homology modeling of human $\beta-G a l$

A structural model of human $\beta$-Gal was constructed using the crystallographic data for $B$. thetaiotaomicron $\beta-G a l$ as a template. The amino acid identity between them was $36 \%$ (Figure 1). According to the sequence alignment, we constructed a model of human $\beta$-Gal composed of 615 amino acids, that is, residues F32 to S646. The

\footnotetext{
Human 26 NATQRMFEIDYSRDSFLKDGQPFRYISGSIHYSRVPRFYWKDRLLKMKMAGLNAIQTYVPWNFHEPWPGQYQFSEDHDVE 105 $\ldots+++||+|\quad|+++|+||||||+++||++|||+|||+|+|||+||||+|+|||+|||||||||+.+|+|||+|++|+$

3d3a 22 SLSEGTFEV--GKNTFLLNGEPFVVKAAEIHYPRIPKEYWEHRIKMCKALGMNTICLYVFWNFHEPEEGRYDFAGQKDIA

Human 106 YFLRLAHELGLLVILRPGPYICAEWEMGGLPAWLLEKESILLRSSDPDYLAAVDKWLGVLLPKMKPLLYQNGGPVITVQV 185 +||$++|+|+||||||||||||||||++|||| \cdot||+.++++++||+|| \cdot|++++++|+++|+++++++|++|||||||+| \mid$

$3 \mathrm{~d} 3 \mathrm{a} \quad 100$ AFCRLAQENGMYVIVRPGPYVCAEWEMGGLPWWLLKKKDIKLREQDPYYMERVKLFLNEVGKQLADLQISKGGNIIMVQV 179

Human 186 ENEYGSYFACDFDYLRFLQKRFRHHLGDDVVLFTTDGAHKTFLKCGALQGLYTTVDFGTGSNITDAFLSQRKCEPKGPLI 265 ||||$|+|++|++|+++|+++++++\ldots++|++|||++\ldots .+.++++++++.+|+.+++.+|++.++.+++++|++|+|$

3d3a 180 ENEYGAF-GIDKPYISEIRDMVKQAGFTGVPLFQCDWNSN--FENNALDDLLWTINFGTGANIDEQFKRLKELRPDTPLM 256

Human 266 NSEFYTGWLDHWGQPHSTIKTEAVASSLYDILARGASVNLYMFIGGTNFAYWNGAN-SPYAAQPTSYDYDAPLSEAGDLT 344 ||||$|+|||++||++++.|++++++.+++|+++|+|+||||+|||||||||+||| . .+.|++|||||||||+|+|++\mid$

3d3a 257 CSEFWSGWFDHWGAKHETRSAEELVKGMKEMLDRNISFSLYMTHGGTSFGHWGGANFPNFSPTCTSYDYDAPINESGKVT 336

Human 345 EKYFALRNIIQKF--EKVPEGPIPPSTPKFAYGKVTLEKLKTVGAALDILCPSGPIKSLYPLTFIQVKQHYGFVLYRTTL 422

||$|.++|+||+++\quad \ldots++++.|\ldots++.+|+++++\ldots+++|+.+\quad+.+++| \ldots|++||+++| .+||+||||++$

3d3a 337 PKYLEVRNLLGNYLPEGETLPEIPDSIPTIAIPTIKMTEMAVLFDNL-----PHPKESEDIRTMEAFDQGWGSILYRTSL 411

Human 423 PQDCSNPAPLSSPLNGVHDRAYVAVDGIPQGVLERN-NVITLNITGKAG-ATLDLLVENMGRVNYGAYINDFKGLVSNLT 500 $+.+.++.+|| ..++||||+|||||+++|+++|+\ldots .++++.+.+++|+||||||||+|||++|+|+|||+++\mid+$

3d3a 412 SASDKEQ---TLLITEAHDWAQVFLNGKKLATLSRLKGEGVVKLPPLKEGDRLDILVEAMGRMNFGKGIYDWKGITEKVE 488

Human 501 LSSNI----LTDWTIFPLDTEDAVRSHLGGWGHRDSGHHDEAWAHNSSNYTLPAFYMGNFSIPSGIPDLPQDTFIQFPGW 576

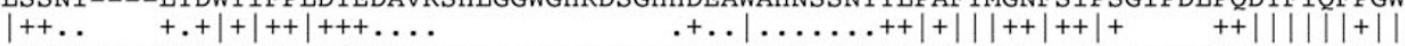

3d3a 489 LQSDKGVELVKDWQVYTIPVDYSFA-------------RDKQYKQQENAENQPAYYRSTFNLNE-----LGDTFLNMMNW 550

Human 577 TKGQVWINGFNLGRYWPARGPQLTLFVPQHILMTSAPNTITVLELEWAPCSSDDPELCAVTFVDRPV---IGSSVTYDH 652

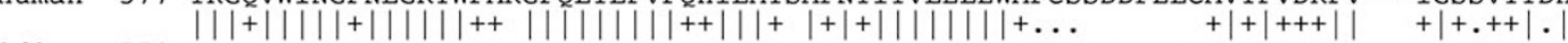

3d3a 551 SKGMVWVNGHAIGRYWEI-GPQQTLYVPGCWLKK-GENEIIILDMAGPSKA-------ETEGLRQPILDVQRGNGAYAH 620
}

Figure 1 Sequence alignment of human $\beta$-Gal (Human) and Bacteroides thetaiotaomicron $\beta$-Gal (3d3a). Sequence identity: 36\%. The alignment was performed using HHpred. ${ }^{7}$ Symbols '., ' '+' and 'l' indicate neutral, good and very good matches, respectively, in the consensus sequence obtained from HHpred server (http://toolkit.tuebingen.mpg.de/hhpred). Using the alignment, a three-dimensional model of human $\beta$-Gal from F32 to S646 (615 amino acids) was constructed by homology modeling with MODELLER. 5,6 
quality of the selected model was superior to that of the other generated models for most of the quality assessment tools and was acceptable. The superpositioning of the human $\beta$-Gal (homology model) with the $B$. thetaiotaomicron $\beta$-Gal (crystal structure) showed a C $\alpha$ RMSD of $0.79 \AA$, indicating that there were no major differences between them in terms of global structure (Figure 2). Furthermore, the conformation of the residues in the active site was well conserved in them.

The structure of human $\beta$-Gal can be divided into three domains. The first domain (F32-S368; 337 residues) comprises a TIM barrel fold and therefore is supposed to contain the active site. The residues comprising the active sites (Y83, I126, A128, E129, N187, E188, E268, Y306 and Y333) and the catalytic residues (E188: the proton donor and E268: the nucleophile) were deduced from the structure of Penicillium sp. $\beta$-Gal (PDB ID: 1TG7, 1XC6). ${ }^{15}$ The first domain is known as the catalytic domain. Both the second (I391-L514; 124 residues) and the third domains (T369-D390, D515-S646; 154 residues) comprise galactose-binding domain-like folds. The human $\beta$-Gal lacks two domains corresponding to domains 2 and 3 of the Penicillium sp. $\beta$-Gal, which consists of five domains. The potential $N$-glycosylation sites (N247, N464, N498, N542, N545 and N555)
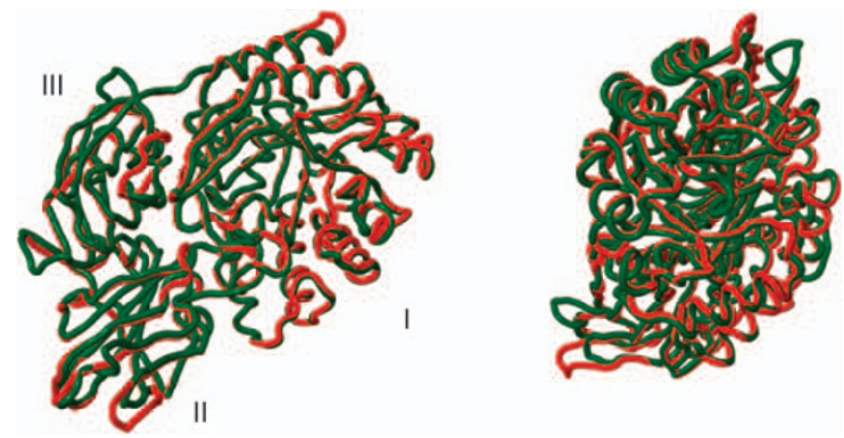

Figure 2 Structure of the human $\beta$-Gal homology model superimposed to the Bacteroides thetaiotaomicron $\beta$-Gal crystal structure. Each backbone is shown as a $\mathrm{C} \alpha$ trace. Red and green indicate $B$. thetaiotaomicron $\beta$-Gal crystal structure and the human $\beta$-Gal model, respectively. Roman numerals indicate the domain numbers. were found in the UniProtKB/Swiss-Prot protein knowledgebase (ID: P16278). ${ }^{34}$ The catalytic residues and $N$-glycosylation sites in the predicted structure of human $\beta-\mathrm{Gal}$ are shown in Figure 3.

\section{Structural changes caused by representative amino-acid substitutions}

G123R. G123 exists at the root of the loop region between the $\mathrm{C}$-terminal end of the $\beta$-strand and the $\mathrm{N}$-terminal end of the $\alpha$-helix in the catalytic domain, and is located near the active site (Figure 3 ). The loop region contains three active site residues (I126, A128 and E129), and interacts with the two loops containing the catalytic residues, namely E188 and E268. The ASA value of G123 is $0 \AA^{2}$ (Table 1), which means that G123 is located in the core region of the enzyme molecule. The numbers of atoms affected by the aminoacid substitutions in the main chain and side chain are 397 and 495, respectively, and the RMSD value is $0.17 \AA$ (Table 1 ). This suggests that G123R causes a large conformational change. Color imaging clearly showed a large conformational change in the core region of the enzyme molecule (Figure 4, G123R). As a result, the enzyme activity of the expressed protein with G123R is almost nil (Table 1).

R201C. R201 is located on the $\alpha$-helix in the catalytic domain, and the side chain of R201 is exposed on the surface (Figure 3 ). The ASA value of R201 is $74 \AA^{2}$ (Table 1), which indicates that R201 exists on the surface of the enzyme molecule (Table 1). The numbers of atoms in the main chain and side chain affected by the amino-acid substitutions are 17 and 27, respectively, and the RMSD value is $0.029 \AA$ (Table 1). The results of the structural study suggest that R201C causes a small conformational change. Color imaging clearly showed a small structural change on the surface of the enzyme molecule (Figure 4, R201C). The results of the expression study showed that it exhibited moderate residual activity (Table 1).

I51T. I51 is located on the $\mathrm{N}$ terminal of the $\beta$-strand in the catalytic domain, and is on the opposite side of the active site (Figure 3). The ASA of I51 is $2.3 \AA^{2}$ (Table 1), which means that this residue does not exist on the surface. In this case, the RMSD value is $0.001 \AA^{2}$, and the numbers of affected atoms in the main and side chains were both determined to be zero under the calculation conditions used in this study (Table 1). This suggests that a very small conformational change

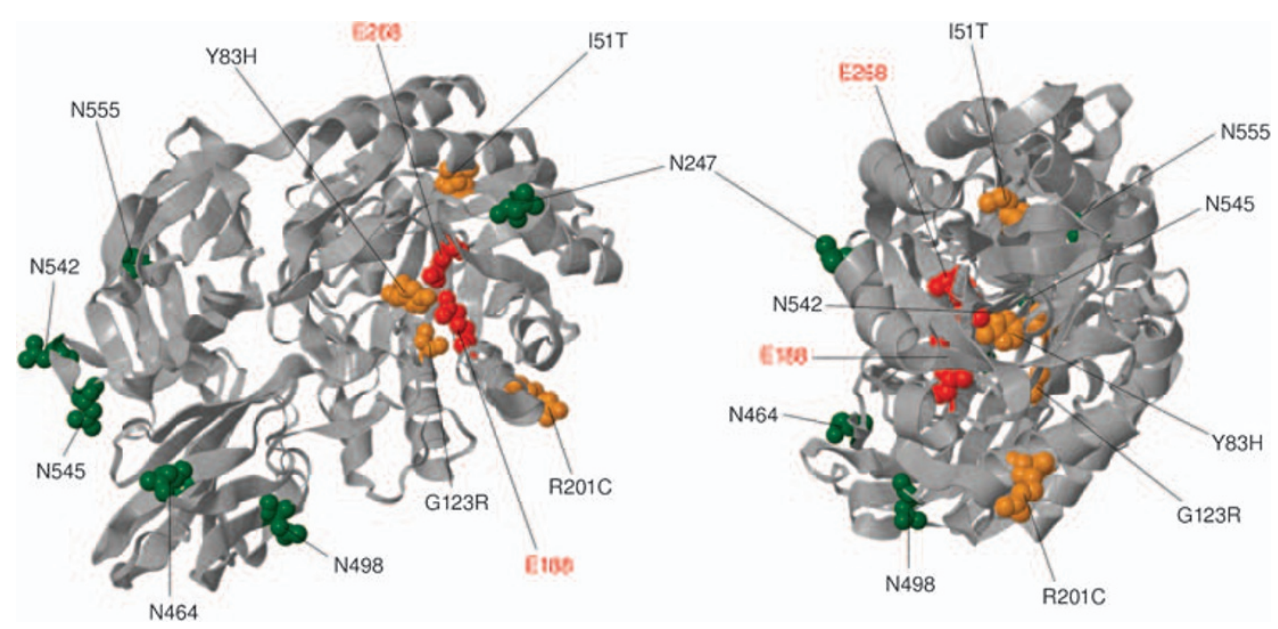

Figure 3 Three-dimensional structure of human $\beta$-Gal and positions of the catalytic residues (E188 and E268), N-glycosylation sites (N247, N464, N498, N542, N545 and N555) and amino-acid residues in which substitutions have been identified (I51T, Y83H, G123R and R201C). Each backbone is shown as a ribbon. The positions of the catalytic residues and $\mathrm{N}$-glycosylation sites are shown by red and green space filling models, respectively. The amino-acid substitutions are shown by orange space filling models. 
Table 1 GM1 gangliosidosis and Morquio B disease mutations, phenotypes and structural changes in the $\beta$-galactosidase protein

\begin{tabular}{|c|c|c|c|c|c|c|c|}
\hline \multirow[b]{2}{*}{ Mutation } & \multirow[b]{2}{*}{ Phenotype } & \multirow{2}{*}{$\begin{array}{l}\text { Expressed enzyme activity } \\
\qquad \text { (\% of normal) }\end{array}$} & \multirow[b]{2}{*}{$A S A\left(\AA^{2}\right)$} & \multirow[b]{2}{*}{$R M S D(\stackrel{\circ}{)}$} & \multicolumn{3}{|c|}{ Number of affected atoms } \\
\hline & & & & & Main chain & Side chain & Active site \\
\hline R201C & Juvenile GM1 & $3-9$ & 74 & 0.029 & 17 & 27 & 0 \\
\hline I51T & Adult GM1 & 27 & 2.3 & 0.0010 & 0 & 0 & 0 \\
\hline Y83H & Morquio B & $2-5$ & 1.4 & 0.081 & 104 & 140 & 9 \\
\hline
\end{tabular}

Abbreviations: ASA, accessible surface area; RMSD, root-mean-square deviation.

Enzyme activity data for the expressed proteins were collected from Ishii et al. ${ }^{22}$ and Yoshida et al. ${ }^{23 .}$
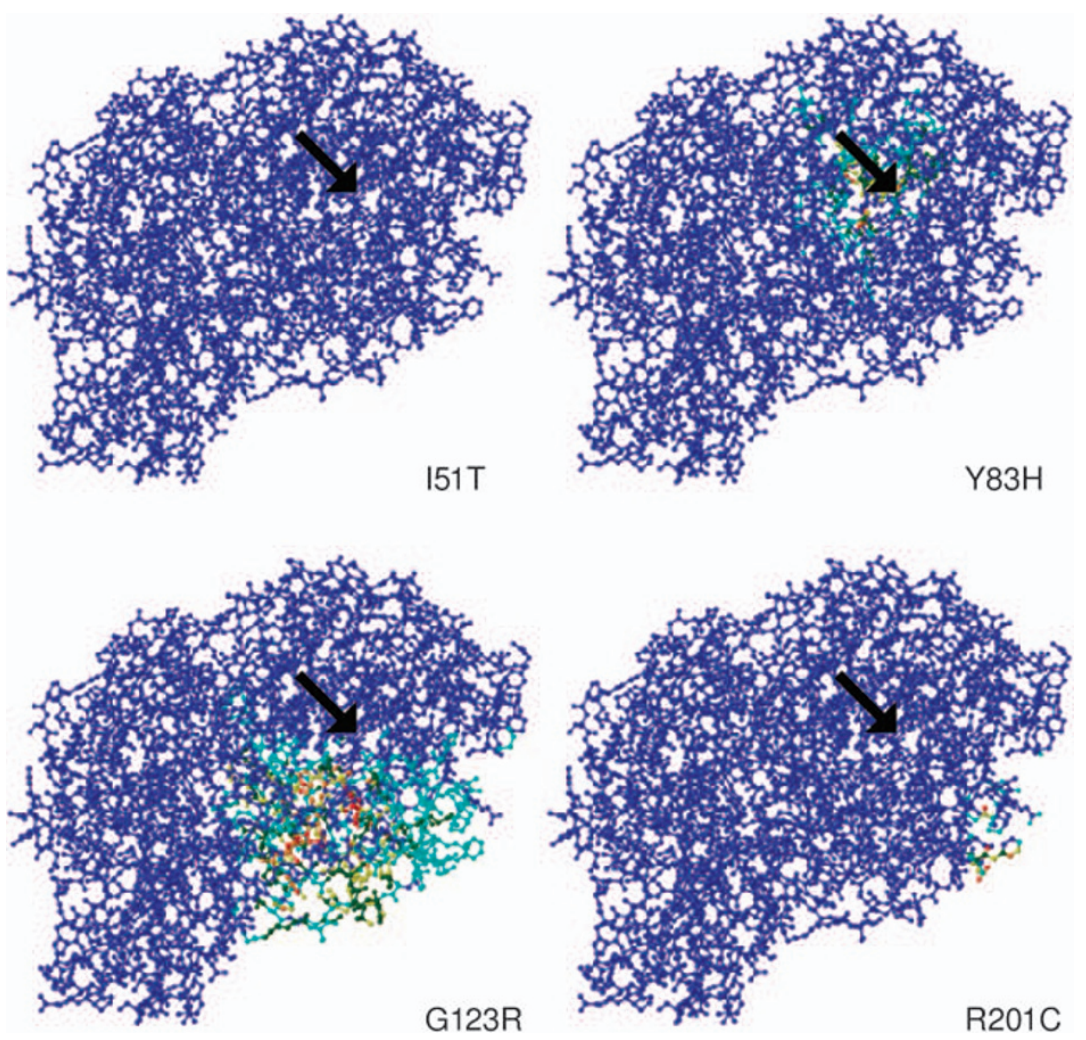

Figure 4 Coloring of the influenced atoms in the three-dimensional structures of the mutant $\beta$-Gals. The distributions of the influenced atoms in the mutant $\beta$-Gals, including G123R, R201C, I51T and Y83H are shown. Each atom is colored according to the distance between the atom in the mutant structure and the corresponding one in the wild type. The colors of the atoms show the distances, as follows: blue $<0.15 \AA$, $0.15 \AA \leqslant c y a n<0.30 \AA$, $0.30 \AA$ green $<0.45 \AA, 0.45 \AA \leqslant$ yellow $<0.60 \AA, 0.60 \AA \leqslant$ orange $<0.75 \AA$, and red $\geqslant 0.75 \AA$. Arrows indicate the location of the active site.

had occurred in the enzyme molecule. Color imaging could not detect this small conformational change (Figure 4, I51T). The results of the expression study showed that the mutant enzyme exhibited considerable residual activity (Table 1 ).

Y83H. Y83 is located in the catalytic domain, and is one of the residues comprising the active site (Figure 3). The ASA value of Y83 is $1.4 \AA^{2}$ (Table 1), suggesting that Y83 exists in the core region of the enzyme molecule. The numbers of affected atoms in the main chain and side chain are 104 and 140, respectively. Among them, the number of affected atoms in the active site is 9. The RMSD value of the Y83M is $0.081 \AA$ (Table 1). This suggests that $\mathrm{Y} 83 \mathrm{H}$ causes a moderate conformational change in the active site. Color imaging clearly demonstrated this (Figure 4, Y83H). There are many polar and/or negatively charged residues in the active site, including Y83 (Figure 5). The tyrosine-to-histidine mutation at position $83(\mathrm{Y} 83 \mathrm{H})$ causes ionic charge change from neutral to positive, and hydrogen bond pattern change in the active site as well as the polar and/or negatively charged residues in the active site are affected by these changes.

\section{DISCUSSION}

As mentioned above, allelic mutations of the $\beta$-Gal gene cause heterogeneous clinical phenotypes, such as GM1 gangliosidosis and Morquio B disease, the former being further classified into three forms, on the basis of the age of onset and severity, infantile, juvenile and adult forms. Heterogeneous patterns of biosynthesis, post-trans- 


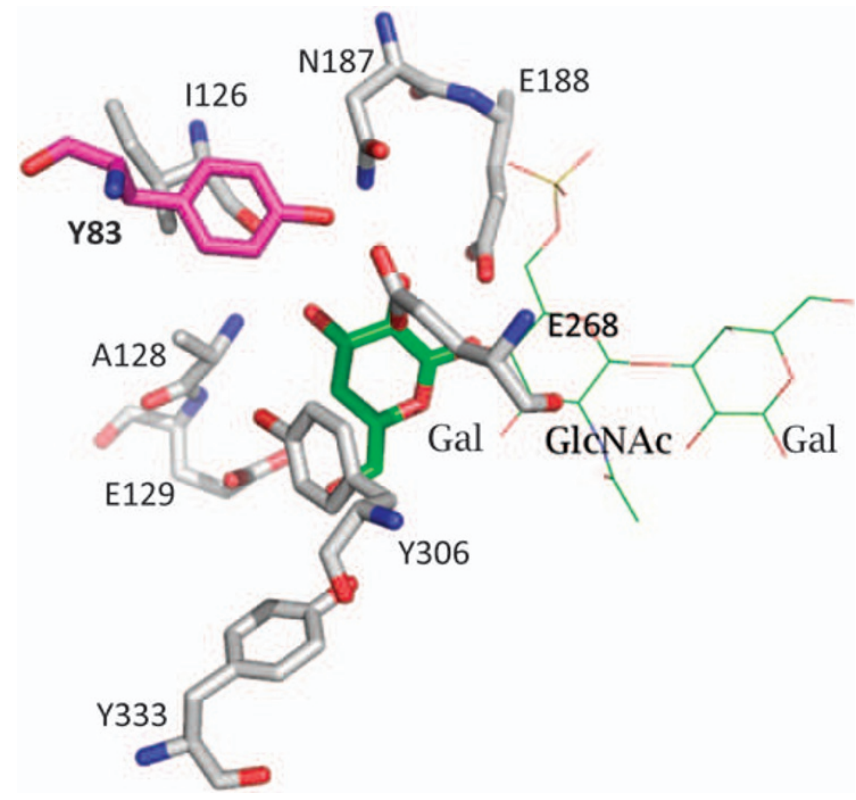

Figure 5 Representation of the active site of the modeled human $\beta$-Gal with keratan sulfate (white: the active site residues, hot pink: Y83 residue, green: keratan sulfate, red: oxygen atoms, blue: nitrogen atoms). The amino-acid substitution from tyrosine to histidine at position $83(\mathrm{Y} 83 \mathrm{H})$ affects the shape of the active site through changes in both ionic charge and hydrogen bond pattern. The terminal galactose of the substrate (green, thick stick) was superimposed from the structure of Penicillium $s p$. $\beta$-Gal (PDB ID: $1 \mathrm{XC6}$ ) and keratan (green, thin wire) was drawn to indicate the entrance of the active site.

lational processing and degradation of the expressed proteins, and their residual enzyme activities were shown in these forms. ${ }^{20,21}$ However, the structural bases of these diseases have not yet been clarified. In this study, we first constructed a structural model of human $\beta$-Gal using the crystallographic structure of $B$. thetaiotaomicron $\beta$-Gal protein as a template.

As the amino acid identity between the two enzymes was sufficiently high, the structural model was believed to be suitable for further investigation, and thus we constructed structural models of representative mutant $\beta$-Gal proteins associated with each clinical phenotype.

G123R is believed to cause a large conformational change in the core region of the catalytic domain, and thus it affects the folding of the protein, which is the rapid degradation of the expressed protein occurring at an earlier stage of biosynthesis. In fact, the expression study showed that the enzyme activity was almost completely deficient in this case. This would lead to the early-onset severe phenotype.

R201C is believed to cause a small conformational change on the surface of the enzyme molecule. The expression study showed that the mutant proteins would not aggregate with lysosomal protective protein, which stabilizes $\beta$-Gal, and most of the synthesized enzyme proteins would be degraded before they reach the lysosomes. ${ }^{21}$ However, small amounts of the enzyme proteins must be transported to the lysosomes and exhibit residual enzyme activity, leading to the intermediate phenotype of the disease.

I51T is believed to cause a very small structural change on the opposite side of the active site in the core region of the catalytic domain. It causes a folding defect, the expressed protein being degraded or defectively processed. The biochemical study showed that the precursor of the mutant enzyme was not phosphorylated and that a small amount of the enzyme protein exhibiting activity reached the lysosomes. ${ }^{21}$ It is believed that the conformational change in this case is very small and that the mutant protein escapes the quality control system in the endoplasmic reticulum, leading to considerable residual enzyme activity and the late-onset mild phenotype of the disease.

In the case of $\mathrm{Y} 83 \mathrm{H}$, it is predicted that a moderate structural change occurs in the active site. This leads to alteration in the pocket shape, which would prevent keratan sulfate from entering the active site. This causes a loss of catalytic activity especially toward glycosaminoglycans containing keratan sulfate.

Previously, we analyzed the kinetic property of mutant $\beta$-Gal from cultured fibroblasts derived from a patient with Morquio B disease having $\mathrm{Y} 83 \mathrm{H}$ and compared it with those obtained from a patient with the adult form GM1 gangliosidosis having I51T and from normal individuals. ${ }^{35}$ The results showed that the mutant $\beta$-Gal of Morquio B disease exhibited lower affinity and lower hydrolytic activity toward Galß1-4GlcNAc, an analog for the repeating disaccharide of keratan sulfate, rather than toward Galß1-3GalNAc, an analog for the sugar chain of GM1 ganglioside, and there were no differences in the affinity and hydrolytic activity between the mutant $\beta$-Gal of the adult form of GM1 gangliosidosis and the wild type. The imbalanced reactivity of the mutant $\beta$-Gal of Morquio B disease would have been caused by the specific structural change in the active site. On the other hand, excessive degradation of the mutant $\beta$-Gal of the adult form of GM1 gangliosidosis having normal affinity toward the substrates would have been caused by the small structural change located far from the active site. Thus, the results of structural investigation could explain the differences in the biochemical phenotype between Morquio B disease and the adult form GM1 gangliosidosis, both of which exhibit residual enzyme activity.

In conclusion, we first constructed a structural model of the human $\beta$-Gal protein and examined the structural changes in mutant $\beta$-Gal proteins due to the representative amino-acid substitutions associated with GM1 gangliosidosis and Morquio B disease. The results show a good correlation between the structural changes in the enzyme molecule, and biochemical and clinical phenotypes in representative cases. Structural investigation is useful for elucidating the bases of these diseases.

\section{CONFLICT OF INTEREST}

The authors declare no conflict of interest.

\section{ACKNOWLEDGEMENTS}

We thank Jay Ponder and colleagues (Washington University) for providing us with the TINKER software. This work was partly supported by grants from the Japan Society for the Promotion of Science, the High-Technology Research Project of the Ministry of Education, Science, Sports and Culture of Japan, the Ministry of Health, Labor and Welfare of Japan, the Japan Science and Technology Agency and the Program for Promotion of Fundamental Studies in Health Sciences of the National Institute of Biomedical Innovation.

1 Suzuki, Y., Oshima, A. \& Nanba, E. $\beta$-Galactosidase deficiency ( $\beta$-galactosidosis): GM 1 gangliosidosis and Morquio B disease. in: The Metabolic and Molecular Bases of Inherited Disease 8th edn. (eds. Scriver C.R., Beaudet A.L., Sly W.S., \& Valle, D.) 3775-3809 McGraw-Hill, New York, NY, 2001).

2 Sinigerska, I., Chandler, D., Vaghjiani, V., Hassanova, I., Gooding, R., Morrone, A. et al. Founder mutation causing infantile GM1 gangliosidosis in the Gypsy population. Mol. Genet. Metab. 88, 93-95 (2006).

3 Brunetti-Pierria, N. \& Scaglia, F. GM1 gangliosidosis: review of clinical, molecular, and therapeutic aspects. Mol. Genet. Metab. 94, 391-396 (2008). 
4 Suzuki, Y., Ichinomiya, S., Kurosawa, M., Ohkubo, M., Watanabe, H., Iwasaki, H. et al. Chemical chaperone therapy: clinical effect in murine GM1-gangliosidosis. Ann. Neurol. 62, 671-675 (2007).

5 Sali, A. \& Blundell, T. L. Comparative protein modeling by satisfaction of spatial restraints. J. Mol. Biol. 234, 779-815 (1993).

6 Fiser, A., Do, R. K. \& Sali, A. Modeling of loops in protein structures. Protein Sci. 9, 1753-1773 (2000).

7 Söding, J. Protein homology detection by HMM-HMM comparison. Bioinformatics 21, 951-960 (2005).

8 Bowie, J. U., Lüthy, R. \& Eisenberg, D. A method to identify protein sequences that fold into a known three-dimensional structure. Science 253, 164-170 (1991).

9 Lüthy, R., Bowie, J. U. \& Eisenberg, D. Assessment of protein models with threedimensional profiles. Nature 356, 83-85 (1992).

10 Wiederstein, M. \& Sippl, M. J. ProSA-web: interactive web service for the recognition of errors in three-dimensional structures of proteins. Nucleic Acids Res. 35, W407-W410 (2007).

$11 \mathrm{Sippl}, \mathrm{M}$. J. Recognition of errors in three-dimensional structures of proteins. Proteins 17, 355-362 (1993).

12 Wallner, B. \& Elofsson, A. Can correct protein models be identified? Protein Sci. 12, 1073-1086 (2003).

13 Wallner, B. \& Elofsson, A. Identification of correct regions in protein models using structural, alignment and consensus information. Protein Sci. 15, 900-913 (2005).

14 Zhou, H. \& Zhou, Y. Distance-scaled, finite ideal-gas reference state improves structurederived potentials of mean force for structure selection and stability prediction. Protein Sci. 11, 2714-2726 (2002)

15 Rojas, A. L., Nagem, R. A. P., Neustroev, K. N., Arand, M., Adamska, M., Eneyskaya, E. V. et al. Crystal structures of beta-galactosidase from Penicillium $s p$. and its complex with galactose. J. Mol. Biol. 343, 1281-1292 (2004)

16 Ward, J. J., Sodhi, J. S., McGuffin, L. J., Buxton, B. F. \& Jones, D. T. Prediction and functional analysis of native disorder in proteins from the three kingdoms of life. J. Mol. Biol. 337, 635-645 (2004).

17 Shimizu, K., Hirose, S. \& Noguchi, T. POODLE-S: web application for predicting protein disorder by using physicochemical features and reduced amino acid set of a position specific scoring matrix. Bioinformatics 23, 2337-2338 (2007).

18 Shimizu, K., Muraoka, Y., Hirose, S., Tomii, K. \& Noguchi, T. Predicting mostly disordered proteins by using structure-unknown protein data. BMC Bioinformatics $\mathbf{8}$, 78 (2007).

19 Ishida, T. \& Kinoshita, K. PrDOS: prediction of disordered protein regions from amino acid sequence. Nucleic Acids Res. 35, W60-W464 (2007).

20 Callahan, J. W. Molecular basis of GM1 gangliosidosis and Morquio disease, type B. Structure-function studies of lysosomal beta-galactosidase and the non-lysosomal betagalactosidase-like protein. Biochim. Biophys. Acta 1455, 85-103 (1999).
21 Oshima, A., Yoshida, K., Itoh, K., Kase, R., Sakuraba, H., Suzuki, Y. Intracellular processing and maturation of mutant gene products in hereditary beta-galactosidase deficiency (beta-galactosidosis). Hum. Genet. 93, 109-114 (1994).

22 Ishii, N., Oohira, T., Sakuraba, H., Endo, F., Matsuda, I., Sukegawa, K. et al. Clinical and molecular analysis of a Japanese boy with Morquio B disease. Clin. Genet. 48 , 103-108 (1995).

23 Yoshida, K., Oshima, A., Shimmoto, M., Fukuhara, Y., Sakuraba, H. et al. Human betagalactosidase gene mutations in GM1-gangliosidosis: a common mutation among Japanese adult/chronic cases. Am. J. Hum. Genet. 49, 435-442 (1991).

24 Takiyama, N., Itoh, K., Shimmoto, M., Nishimoto, M., Inui, K., Sakuraba, H. et al. Molecular form and subcellular distribution of acid $\beta$-galactosidase in fibroblasts from patients with Morquio B disease and galactosialidosis. Brain Dev. 19, 126-130 (1997).

25 McDonald, I. K. \& Thornton, J. M. Satisfying hydrogen bonding potential in proteins. J. Mol. Biol. 238, 777-793 (1994).

26 Kundrot, C. E., Ponder, J. W. \& Richards, F. M. Algorithms for calculating excluded volume and its derivatives as a function of molecular conformation and their use in energy minimization. J. Comput. Chem. 12, 402-409 (1991).

27 Dudek, M. J. \& Ponder, J. W. Accurate modeling of the intramolecular electrostatic energy of proteins. J. Comput. Chem. 16, 791-816 (1995).

28 Kong, Y. \& Ponder, J. W. Reaction field methods for off-center multipoles. J. Chem. Phys. 107, 481-492 (1997).

29 Pappu, R. V., Hart, R. W. \& Ponder, J. W. Analysis and application of potential energy smoothing for global optimization. J. Phys. Chem. B 102, 9725-9742 (1998).

30 Ren, P. \& Ponder, J. W. Polarizable atomic multipole water model for molecular mechanics simulation. J. Phys. Chem. B 107, 5933-5947 (2003).

31 Kabsch, W. A discussion of the solution for the best rotation to relate two sets of vectors. Acta Cryst. A 34, 922-923 (1978).

32 Matsuzawa, F., Aikawa, S., Doi, H., Okumiya, T. \& Sakuraba, H. Fabry disease: correlation between structural changes in $\alpha$-galactosidase, and clinical and biochemical phenotypes. Hum. Genet. 117, 317-328 (2005).

33 Weiner, S. J., Kollman, P. A., Case, D. A., Singh, C. U., Ghio, C., Alagona, G. et al. A new force field for molecular mechanical simulation of nucleic acids and proteins. J. Am. Chem. Soc. 106, 765-784 (1984).

34 The UniProt Consortium. The universal protein resource (UniProt). Nucleic Acids Res. 36, D190-D195 (2008)

35 Okumiya, T., Sakuraba, H., Kase, R. \& Sugiura, T. Imbalanced substrate specificity of mutant $\beta$-galactosidase in patients with Morquio B disease. Mol. Genet. Metab. 78, 51-58 (2003). 